\title{
A Simulation Study of an Advanced Thermal Management System for Heavy Duty Diesel Engines
}

\author{
Waleed Nessim \\ Laboratory of Vehicle Power-train System \\ School of Mechanical Engineering \\ Beijing Institute of Technology \\ Beijing, China \\ waleed_nessim@yahoo.com \\ Zhao Changlu \\ Laboratory of Vehicle Power-train System \\ School of Mechanical Engineering \\ Beijing Institute of Technology \\ Beijing, China \\ zhao@bit.edu.cn
}

\author{
Fujun Zhang \\ Laboratory of Vehicle Power-train System \\ School of Mechanical Engineering \\ Beijing Institute of Technology \\ Beijing, China \\ zfj123@bit.edu.cncl \\ Zhu Zhenxia \\ Laboratory of Vehicle Power-train System \\ School of Mechanical Engineering \\ Beijing Institute of Technology \\ Beijing, China \\ zhuzhenxia@163.com
}

\begin{abstract}
The trend toward high power density engines has led to new implementation of more intelligent thermal management systems. Advanced thermal management systems for internal combustion engines can help in reducing the fuel consumption, pollutant emissions, warm up time, noise level as well as improving comfort and engine durability. In this study, the effect of advanced thermal management system on heavy duty (HD) diesel engine was investigated using FTP-75 driving cycle. Firstly, the cooling system model was validated with experimental data, and then replaced with an advanced thermal management system with PID feedback control using a 1-D simulation model. The simulation results showed a reduction in the time of cold start by $50 \%$, reduction in power consumption of the cooling system by $13 \%$, decrease fuel consumption $(4: 11) \%$ and decreasing the total frictional torque by $10 \%$. This study investigates how the thermal management system enhances the overall HD diesel engine efficiency.
\end{abstract}

Keywords-HDDE; thermal management; warm up; fuel economy; friction

\section{INTRODUCTION}

Recently modern engine require a complicated cooling system to control the temperature of many fluids such as coolant fluid, oil, freon, charged air and even the diesel fuel. Such sophisticated requirements can place an overwhelming demands on all types of belt drive cooling systems since they can consume up to $15 \%$ of the engine available horsepower when operating at high peak loads. Another drawback is that they reduce overall performance and efficieny because such fans and pumps have great difficulty in correctly monitoring and maintain the multible operating temperature levels. Conventional cooling system is generally not very accurate, not controllable and lead to considerable parasitic losses [1]. It is designed to just guarantee a sufficient heat removal at maximum engine output conditions at the worst vehicle operating conditions (low vehicle speed and high ambient temperature) However, these operational conditions only represent approximately $5 \%$ of the conditions that the vehicle will encounter during its life [2]. This approach results in poor fuel economy which could be enhanced with advanced thermal management systems.

However one-dimensional thermal fluid analysis does not provide detailed fluid flow analysis inside a water jacket, it enables the entire cooling system control to be studied and the piping to be optimized. It also facilitates transitional calculations of the mode drive, which are difficult with three-dimensional analysis [3].

In this work one-dimensional thermal fluid analysis software "GT-SUITE" was used to simulate the conventional cooling system then after validation, the cooling system was modified with an advanced thermal management system. The objective of this work is to conduct simulation studies to evaluate the impact of advanced thermal management system on the engine thermal state, fuel economy and engine friction.

\section{THERMAL MANAGEMENT}

The term "thermal management" describes the efficient control of thermal energy flows in the vehicle in accordance with the specific requirements and the prevailing operating and load conditions. As a result, vehicle emissions can be reduced, also the thermal state, friction torque and mechanical engine efficiency can be improved. This leads to lower fuel consumption, longer engine life and upswing in thermal comfort. 
The key benefits of thermal management systems can be summarized as follow:

- $\quad$ Reduce parasitic power losses.

- Improve cooling system control.

- Quicker engine warm-up during cold start.

- Reduce engine wear and friction.

- Increase lubricant life.

- Increase average combustion temperature.

- Enhance fuel economy.

- Decrease exhaust emissions.

- Eliminating hot soak after engine stop.

\section{THERMAL BALANCE EXPERIMENT}

Engine thermal loads are created through the conversion of chemical energy to thermal and mechanical energy and the transfer of that energy through the powertrain. About $40 \%$ of fuel energy goes to produce the effective power, $30 \%$ leaves through the exhaust and 30\% leaves through the coolant system. Engine heat rejection via cooling system was calculated via special test rig as shown in Fig.1.

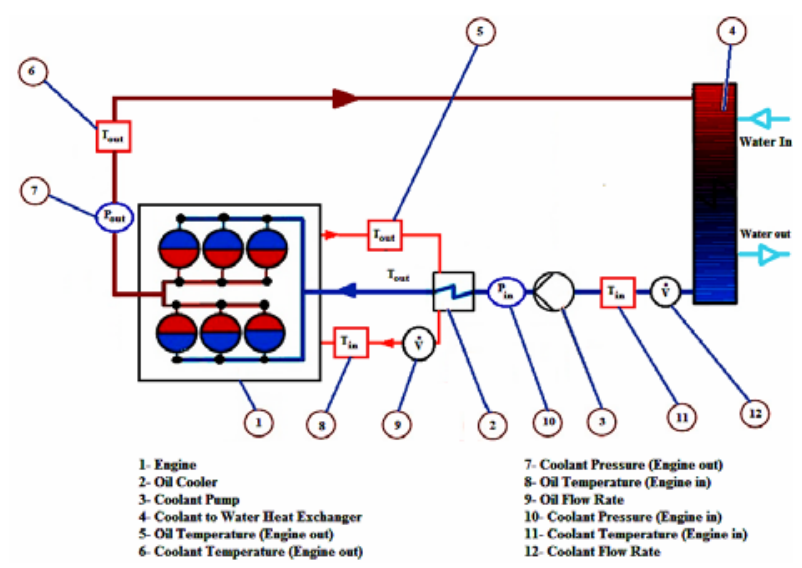

Figure 1. Diesel engine thermal balance experiment

In this test rig, the original radiator in the vehicle is emulated by an intensive heat exchanger which is cooled by the outside cold water. The temperature and pressure of coolant entering and leaving the engine were measured by setting two temperature and pressure sensors; also a flow sensor was fixed after the heat exchanger to measure the coolant flow rate.

The heat rejection from the engine to coolant was calculated by using the following equation:

$$
\begin{gathered}
Q_{c}=\dot{m}_{c} C_{p}\left(T_{2}-T_{1}\right) \\
\dot{m}_{c}=\rho_{c} \dot{V}_{c}
\end{gathered}
$$

Where:
Q
$\dot{m}_{c}$ Coolant mass flow rate $(\mathrm{kg} / \mathrm{s})$

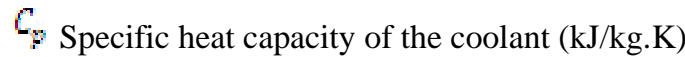

$T_{1}$ Temperature at engine inlet $(\mathrm{K})$

$T_{2}$ Temperature at engine outlet $(\mathrm{K})$

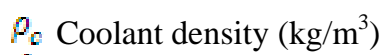

$V_{c}$ Coolant volume flow rate $\left(\mathrm{m}^{3} / \mathrm{s}\right)$

\section{SySTEM MODELING}

TCD 6V2015 diesel engine with its cooling system was used to configure the cooling system model by using one dimensional simulation program GT-Suite (GT-COOL, GTPOWER) program.

\section{A. Engine Model}

GT-POWER uses one dimensional gas dynamics to represent the flow and heat transfer in the components of the engine model [4]. The engine has been modeled with GTPOWER and validated using the experimental data of engine performance which has conducted in "Power Mechanism and Engineering Laboratory, BIT”. The main engine data are listed in table 1. Fig. 2 shows a comparison of the measured and predicted cylinder pressure with crank angel. The peak pressure and the pressure gradient produced by simulation are matched closely with measurements with less than $4.56 \%$ error. The GT-POWER engine model was used to obtain Fuel map, Heat rejection map and Friction map.

TABLE I. ENGINE MAIN DATA

\begin{tabular}{|c|c|c|}
\hline \multirow{4}{*}{$\begin{array}{c}\text { Engine } \\
\text { Characteristic } \\
\text { Parameters }\end{array}$} & Compression ratio & 17.5 \\
\cline { 2 - 3 } & Firing order & A1 B3 A3 B2 A2 B1 \\
\cline { 2 - 3 } & Cylinder arrangement & V form at angle 90 ${ }^{\circ}$ \\
\cline { 2 - 3 } & Working cycle & 4 Stroke \\
\cline { 2 - 3 } & Number of cylinders & 6 \\
\hline \multirow{2}{*}{$\begin{array}{c}\text { Cylinder } \\
\text { Geometry }\end{array}$} & Rated speed range (rpm) & $1800: 2100$ \\
\hline \multirow{3}{*}{ Fuel Injection } & Bore/Stroke (mm) & $132 / 145$ \\
\cline { 2 - 3 } & Engine Displacement (ltr.) & 11906 \\
\cline { 2 - 3 } & Injection advance angle & \\
\cline { 2 - 3 } & Nozzle diameter (mm) & 0.25 \\
\hline
\end{tabular}

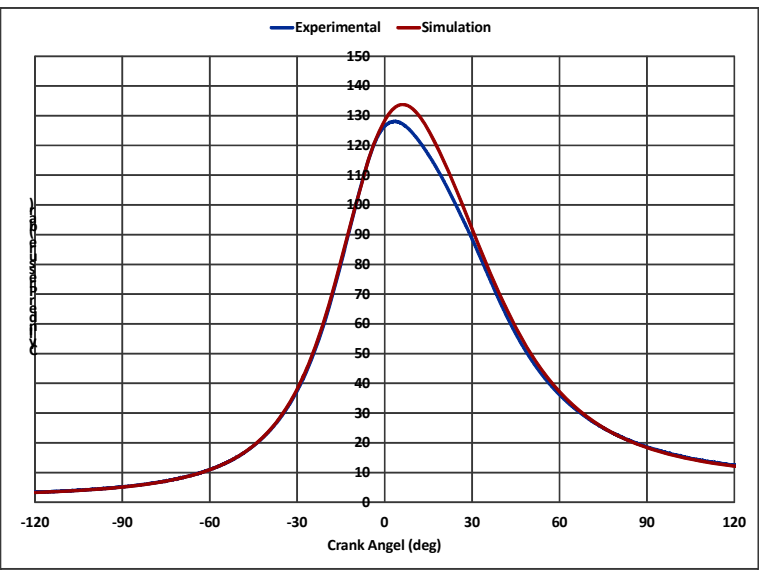

Figure 2. Engine Model Validation (1600 rpm, Full Load)

\section{B. Cooling Model}

GT-Cool is based on one-dimensional fluid dynamics, representing the flow and heat transfer in the pipe and the 
other components of a cooling system [5]. It is a module-based code that provides flexible model building capability. The specifications of engine cooling system are listed in table 2. Fig. 3 shows a comparison of the measured and predicted engine heat rejection

TABLE II. COOLING SYSTEM SPECIFICATIONS

\begin{tabular}{|c|c|}
\hline Coolant volume in engine (ltr) & 17 \\
\hline Coolant volume in radiator (ltr) & 20 \\
\hline Temperature of thermostat begin to open $\left({ }^{\circ} \mathrm{C}\right)$ & 83 \\
\hline Maximum heating up of coolant by engine $\left({ }^{\circ} \mathrm{C}\right)$ & 9 \\
\hline Coolant volume flow rate at $2100 \mathrm{rpm}(\mathrm{ltr} / \mathrm{min})$ & 375 \\
\hline Diameter of pipes on radiator $(\mathrm{mm})$ & 70 \\
\hline Total radiator volume $(\mathrm{ltr})$ & 444 \\
\hline Temperature at full load and rated speed $\left({ }^{\circ} \mathrm{C}\right)$ & 95 \\
\hline Maximum coolant temperature at engine outlet $\left({ }^{\circ} \mathrm{C}\right)$ & 103 \\
\hline Ambient temperature [inlet air to HX] $\left({ }^{\circ} \mathrm{C}\right)$ & 40 \\
\hline Radiator core Area (m $\left.{ }^{2}\right)$ & 0.8 \\
\hline Engine structural volume [Block+Head] $(\mathrm{ltr})$ & 200 \\
\hline Engine structural surface area [Block+Head] $\left(\mathrm{m}^{2}\right)$ & 2.5 \\
\hline
\end{tabular}

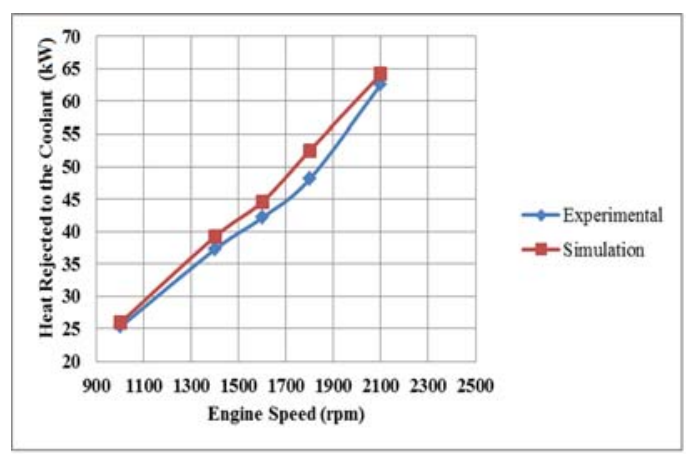

Figure 3. Cooling Model Validation (at half load)

The results produced by simulation are matched closely with measurements with less than $1.56 \%$ error. Fuel map, Heat rejection map and Friction map which obtained from GTPOWER were used in order to simulate engine cooling system. These results indicate that this cooling system model is capable of simulating cooling system behavior during steady and transient engine condition and evaluating the cooling system performance.

\section{Integrated Engine and Cooling System Model}

The engine and the thermal management system that encompasses it have inherent interactions. These interactions have a pronounced effect on both systems. For this reason, an integrated model for the engine and its conventional cooling system was established with GT-SUITE program

\section{Advanced Thermal Management Model}

Conventional cooling system has been replaced with an advanced thermal management system using GT-SUITE simulation program. The model consists of four circuits, as shown in Fig. (4), the connections between the engine and the cooling system were made at the interfaces between engine and the thermal management system. The effect of controlled system on warm up period, engine friction and the fuel economy at different coolant temperatures were evaluated. A control loop feedback mechanism was applied to the controlled system by using (PID) controller.

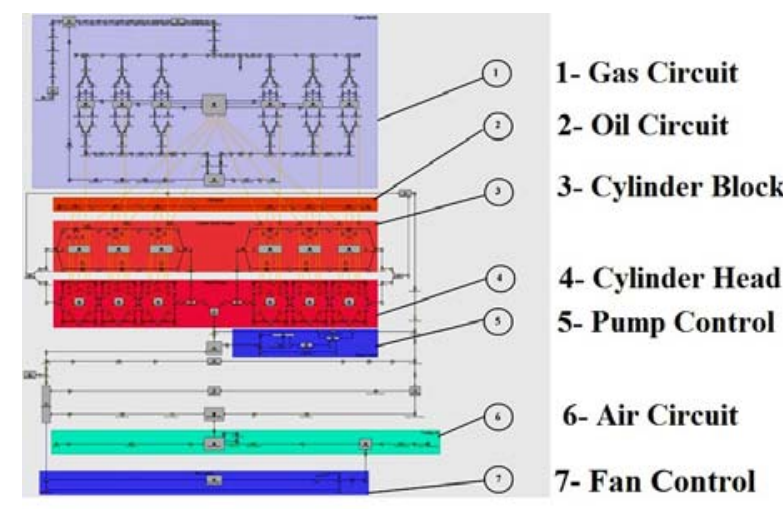

Figure 4. Advanced detailed cooling system model

\section{RESULTS AND ANALYSIS}

Fig. 5 illustrates the temperature of the coolant exit from the engine at cold start $(\mathrm{rpm}=1000)$. It compares between the conventional cooling system and the electric control one which use electric pump, electric fan, and electric valve. As shown in this figure, the warm up period has been decreased about $50 \%$ this improvement due to the operation of conventional thermostat does not give precise control needed for the cooling systems because the wax thermostat has slow response and unnecessary temperature fluctuation and lack of accuracy, It is a single point controllers only activated at a certain coolant temperature.

Fig. 6 illustrates the effect of increasing the oil sump temperature on frictional torque at half load, $1000 \mathrm{rpm}$, it is clear that the frictional torque could be reduced by $10 \%$ if the temperature of the oil sump was increased from 80 to 110 . This reduction can be related to the drop in the oil viscosity.

Fig. 7 shows the effect of control cooling system on the specific saving on using FTP-75 driving cycle. The electrical controlled system can save the fuel with $4.4 \%$ at warm up and with $10.1 \%$ at the whole driving cycle due to the control of pump and fan speed and flow rate.

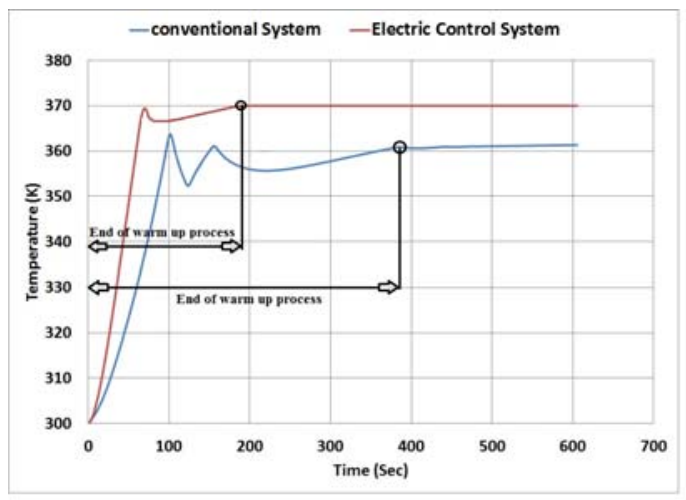

Figure 5. Advanced detailed cooling system model 


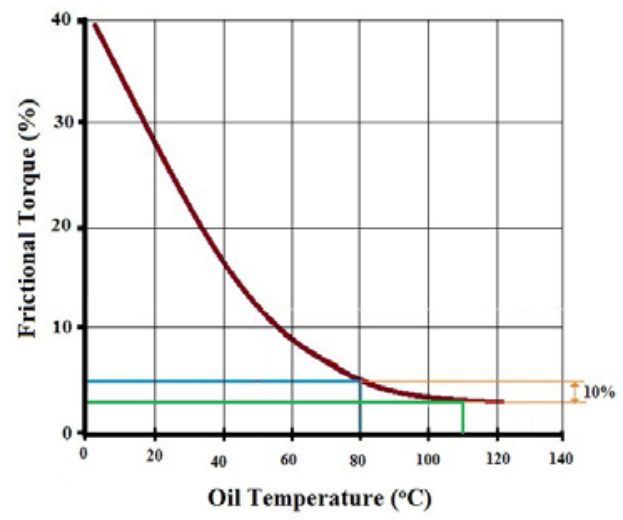

Figure 6. Advanced detailed cooling system model

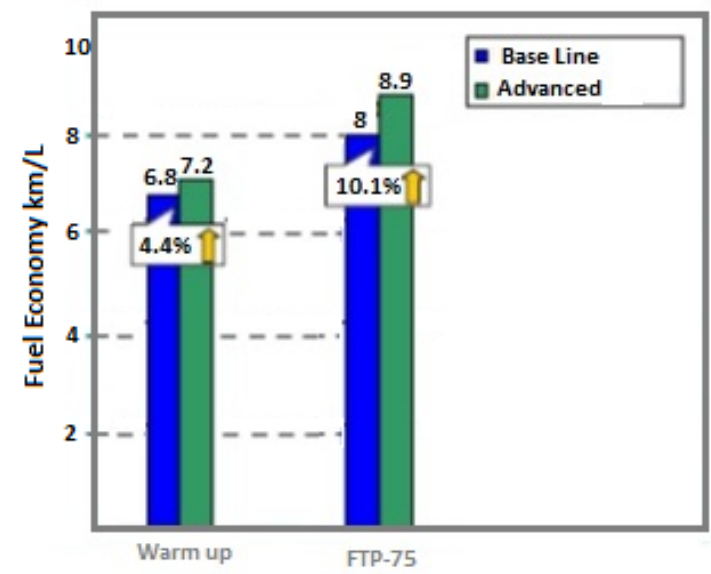

Figure 7. Advanced detailed cooling system model

The electric valve was used to raise the coolant temperature higher than with a conventional thermostat (from $90^{\circ} \mathrm{C}$ to $98^{\circ} \mathrm{C}$ ) to improve the cold start and warm up process. In this manner the engine can run warmer than normal which can enhance combustion along the walls, improve heat flow and obtain higher combustion temperatures which enhance engine performance and reduce the fuel consumption.

\section{CONCLUSION}

The detailed cooling system model for TCD 6V2015 diesel engine was configured with commercial code, GT-SUITE. The simulation results were compared with experimental data in order to validate the conventional cooling system model then a controlled cooling system model was conducted to study its effect on engine performance. The computer controlled cooling system met the objectives of increasing coolant temperatures to the optimum working temperatures which led to fuel saving

The main conclusions of this research are summarized as follows:

- $\quad$ Reducing the parasitic losses for pump and fan.

- Controlling the pump speed and fan speed to increase the engine thermal efficiency.

- Using electric thermostat to reduce the pressure resistance and increase its response.

In addition, the use of this detailed model will enable the investigation of more innovative control systems for both existing and proposed hardware, even using Hardware-in-theLoop (HIL) simulations to prove new ideas.

\section{ACKNOWLEDGMENT}

The authors would like to thank Laboratory of Vehicle Power-train System team, Beijing Institute of Technology for their support and encouragement to publish this paper.

\section{REFERENCES}

[1] Hnatczuk, W., Lasecki, M.P., Bishop, J., Goodell, J., "Parasitic Loss Reduction for 21 ${ }^{\text {st }}$ Century Trucks,” SAE Paper 2000-01-3423, 2000.

[2] Chad Lehner, Gordon Parker, Oner Arici and John Johnson, "Design and Development of a Model Based Feedback Controlled Cooling System for Heavy Duty Diesel Truck Applications using a Vehicle Engine CoolingSystem Simulation, ” SAE Paper, 2001-01-0336, 2006.

[3] Filip Kitanoski, Wolfgang Puntigam, Martin Kozek, Josef Hanger., "An Engine Heat Transfer Model for Comprehensive Thermal Simulations,” SAE Paper, 2006-01-0882, 2006.

[4] GT-SUITE manual, Gamma Technologies, 2009.

[5] Installation manual liquid cooled diesel engine, DEUTZ, 2000. 